\title{
ESTUDIOS ESTRUCTURA Y FUNCIÓN DE UNA LECTINA AISLADA DE SEMILLAS DE CAESALPINIA SPINOSA KUNTZE (TARA)
}

\author{
STRUCTURE AND FUNCTION STUDIES OF A LECTIN FROM CAESALPINIA \\ SPINOSA KUNTZE (TARA) SEEDS
}

\author{
Werner Mendoza ${ }^{1}$; Laura Gandolfo ${ }^{2}$; Luis Ponce ${ }^{3 *}$;osé Novello ${ }^{3}$; Sergio Marangoni ${ }^{3}$
}

\begin{abstract}
RESUMEN
Una lectina de semillas de Caesalpinia spinosa Kuntze (Tara; Caesalpiniaceae, Leguminosae) fue purificada y caracterizada a través de extracción salina, por combinación de dos cromatografías de exclusión molecular y HPLC de fase reversa. El análisis en SDS-PAGE demostró que la lectina purificada era homogénea ya que ésta presentó una sola banda de proteína correspondiente a un tamaño molecular de $29 \mathrm{kDa}$. La lectina de Caesalpinia spinosa Kuntze (CsLEC) fue capaz de aglutinar eritrocitos del grupo sanguíneo humano "B" $\mathrm{Rh}+$ con una $\mathrm{CMH}$ de $3,86 \mu \mathrm{g} / \mathrm{ml}$ y esta actividad fue inhibida por D-glucosa, D-manosa, D-maltosa, D-glucosamina, N-acetil glucosamina $(3,25 \mathrm{mM})$ y el agente quelante EDTA $(0,31 \mathrm{mM})$, lo que sugiere que puede ser considerada como una lectina tipo $\mathrm{C}$ que depende de iones divalentes como calcio y manganeso. El análisis completo de aminoácidos reveló que CsLEC es ácida y sumamente hidrofóbica (16,3\% residuos ácidos, 8,9\% básicos, 17,0\% neutros y $57,8 \%$ residuos hibrofóbicos), prevaleciendo la fenilalanina (Phe, 22,1\%). Comparación de la secuencia aminoacídica con otras secuencias de vegetales determinó que CsLEC tiene homología con lectinas de la familia Leguminosae, mostrando una semejanza del 67,9\% con la leucoaglutinina de Maackia amurensis (Fabaceae, Papilionoideae) con sialillactosa y el precursor de la lectina de Maackia amurensis.
\end{abstract}

Palabras clave: Caesalpinia spinosa Kuntze, lectina, fitohemaglutinina, defensa de la planta.

\begin{abstract}
A lectin from Caesalpinia spinosa Kuntze (tara; Caesalpiniaceae, Leguminosae) seeds was purified and characterized through saline extraction by the combination of two size-exclusion chromatographies and a reverse phase HPLC. The SDS-PAGE analysis demonstrated that the purified lectin was homogeneous since it presented a single protein band corresponding to a molecular size of $29 \mathrm{kDa}$. The lectin from Caesalpinia spinosa Kuntze (CsLEC) was able to agglutinate human blood group " $B$ " Rh+ erythrocytes with a CMH of $3.86 \mu \mathrm{g} / \mathrm{ml}$. This activity was inhibited by D-glucose, D-maltose, D-mannose, D-glucosamine, $N$-acetyl glucosamine $(3.25 \mathrm{mM})$ and the chelanting agent EDTA $(0.31 \mathrm{mM})$, suggesting that it can be considered as a type $C$ lectin, which depend on divalent ions such as calcium or manganese. The complete amino acid analysis revealed that the CsLEC is acidic and highly hydrophobic (16.3\% acid , $8.9 \%$ basic, $17.0 \%$ neutral and $57.8 \%$ hydrophobic residues), prevailing phenylalanin (Phe, 22.1 $\%)$. Amino acid sequence comparison with other plant lectins determined that it has more homology with the lectins from the Leguminosae family, showing $67.9 \%$ similarity with the leucoagglutinin from Maackia amurensis (Fabaceae, Papilionoideae) with sialillactose and the predecessor of the lectin from Maackia amurensis.
\end{abstract}

Key words: Caesalpinia spinosa Kuntze, lectin, phytohemagglutinin, plant defense.

1 Facultad de Ciencias Biológicas y Agropecuarias, Escuela de Postgrado, Universidad de San Agustín, Arequipa, Perú. E-mail: wermen2005@peru.com

2 Facultad de Ciencias, Escuela de Biología, Universidad Nacional Jorge Basadre Grohmann, Tacna, Perú. E-mail: yesminn@ hotmail.com

3 Laboratory of Chemistry of Proteins, Department of Biochemistry, University State of Campinas, SP, Brazil.

* Corresponding author: E-mail: poncesoto@yahoo.com.ar

Fecha de Recepción: 01 Agosto 2006

Fecha de Aceptación: 11 Septiembre 2006 


\section{INTRODUCCIÓN}

Las lectinas son proteínas capaces de unir moléculas de azúcar y son ubicuas en organismos vivos. El término lectina, propuesto por Boy y Sharpleigh en 1954, deriva del latín legere (seleccionado, escogido) y se refiere a la capacidad de unión selectiva de azúcares particulares. Este término fue generalizado desde 1972 para todas aquellas proteínas ligadoras de azúcares y aglutinadoras de células que no poseen un origen inmune y son encontradas en animales, vegetales y microorganismos (Sharon y Lis, 1989). Las semillas de leguminosas son particularmente fuentes ricas de lectinas (Carlini y Grossi-de-Sá, 2002).

En los vegetales, la mayoría de las lectinas se encuentran en órganos de reserva, lo cual es una evidencia indirecta de su papel como proteínas de defensa. Aún después del descubrimiento de las lectinas, los científicos han estado intrigados por sus posibles papeles biológicos. Un avance se presentó cuando se comprendió que la mayoría de las lectinas vegetales no sólo cumplen un papel en la misma planta, por ejemplo, como una fuente de nitrógeno o como un factor de reconocimiento específico, sino que también interactuarían con glucoconjugados de otros organismos (Peumans y Van Damme, 1995). Las lectinas presentan actividad antiviral, antibacteriana, antifúngica, insecticida y antitumoral (Hudak et al., 2000; Ayouba et al., 1994; Peumans y Van Damme, 1995; Zhu et al., 1993; Castillo-Villanueva y Abdullaev, 2005).

El presente trabajo tiene por objetivo hacer una descripción de la estructura y función de una lectina aislada a partir de semillas de Caesalpinia spinosa Kuntze (Tara), pues esta especie además de ser endémica del Perú presenta pocos problemas con plagas, lo cual indicaría el papel de las lectinas en su mecanismo de defensa.

\section{MATERIALES Y MÉTODOS}

Material vegetal: Semillas de tara, Caesalpinia spinosa Kuntze (Caesalpiniaceae, Leguminosae), que fueron recolectadas de la localidad de Pachia, Provincia de Tacna $\left(16^{\circ} 44^{\prime}\right.$ ' " latitud sur y entre $70^{\circ} 16^{\prime}$ 0" y $71^{\circ} 8^{\prime} 16^{\prime \prime}$ longitud oeste).

Extracción salina: De acuerdo al método de Villarrubia et al. (1995), $100 \mathrm{~g}$ de semillas enteras fueron trituradas en un molino de maíz hasta la ob- tención de un material pulverizado, de los cuales $70 \mathrm{~g}$ de harina fueron disueltos en $210 \mathrm{ml}$ (proporción 1:3 v/v) de una solución de $\mathrm{NaCl} 10 \%$ dentro de un vaso de $500 \mathrm{ml}$. La mezcla resultante fue mantenida en agitación por 1 hora a temperatura ambiente, para obtener la solubilización de las proteínas. Posteriormente la suspensión obtenida fue filtrada en gasa, a fin de retirar las partículas grandes y materiales insolubles, y centrifugada a $3.000 \mathrm{x}$ g por 20 minutos a $4^{\circ} \mathrm{C}$. El precipitado se descartó y el sobrenadante obtenido (120 ml) fue dializado en 1 litro de tampón bicarbonato de amonio $\left(\mathrm{NH}_{4} \mathrm{HCO}_{3}\right)$ 0,1 M, pH 8,0, por 6 horas (realizándose cambios cada 2 horas) con la ayuda de un agitador magnético. La eliminación de sal fue comprobada añadiendo gotas de nitrato de plata (AgNO3) 0,01 N (de haber presencia de $\mathrm{NaCl}$, la solución adquiría una coloración lechosa). Dos alícuotas de $0,1 \mathrm{ml}$ fueron tomadas para la determinación de proteínas por el método de Biuret y la prueba de hemaglutinación con eritrocitos humanos. El dializado fue conservado a $4{ }^{\circ} \mathrm{C}$.

Cromatografía de exclusión molecular: Para la purificación de la muestra anterior se colocó $25 \mathrm{ml}$ en una columna de exclusión molecular empacada con Sephadex G-100 (1,6 x $100 \mathrm{~cm})$ según Toyama et al. (2001). Luego, $126 \mathrm{ml}$ de la muestra anterior fueron pasados por una columna de Sephadex G-75 (1,9 x 102 cm) según Toyama et al., 2001.

HPLC de fase reversa: $20 \mathrm{mg}$ de fracción con actividad hemaglutinante y de afinidad por carbohidratos de la etapa anterior fue purificada en una columna preparativa $\mu$-Bondapack C18 $(0,78 \times 30 \mathrm{~cm})$, previamente equilibrada con ácido trifluoracético 0,1\%, pH 3,5 (Tampón A), acoplada a un sistema de HPLC de fase reversa, según Freire et al. (2001). El sistema cromatográfico empleado fue el HPLC-PDA 991 (Waters) equipado con dos bombas modelo 510/B (Waters) y un inyector automático de muestras U6K con un asa de 2,0 $\mathrm{ml}$ de capacidad. Inicialmente la elusión de la muestra fue realizada a través de un gradiente lineal $(0-100 \%)$ con acetonitrilo $66 \%$ (v/v) (Tampón B). Las fracciones fueron monitoreadas a $280 \mathrm{~nm}$.

Electroforesis SDS-PAGE: La electroforesis en gel de poliacrilamida fue realizada de acuerdo a la metodología descrita por Laemmli (1970). Para la determinación de la masa molecular de la fracción con actividad hemaglutinante (CsLEC) se usó el programa Origin 6.0 (CA, USA) 
Prueba de hemaglutinación: La actividad hemaglutinante de la lectina fue ensayada según lo descrito por Costa et al. (1999) en eritrocitos intactos y sobre eritrocitos tripsinizados de humano de los grupos sanguíneos del sistema $\mathrm{ABO}$, todos factor Rhesus positivo $\left(\mathrm{Rh}^{+}\right)$. La sangre fue recolectada y mantenida en una solución de Alsever (2,05\% glucosa, $0,80 \%$ citrato de sodio y $0,42 \% \mathrm{NaCl}, \mathrm{pH} 6,1$ ajustado con ácido cítrico) a $4{ }^{\circ} \mathrm{C}$ hasta su uso.

Actividad hemaglutinante: Se realizó según lo descrito por Carvalho et al. (1998). Para la determinación de la actividad hemaglutinante de la lectina de tara fueron empleadas placas de microtitulación de 96 pozos (Sigma Chemical Co., USA.). En cada pozo de las primeras filas se adicionaron $50 \mu \mathrm{lde}$ CTBS e inmediatamente después $50 \mu \mathrm{l}$ de la lectina. La muestra fue diluida seriadamente, con agitación $\mathrm{y}$ transferencia de $50 \mu \mathrm{l}$ para el pozo siguiente hasta la penúltima fila. Los primeros pozos sin muestra pero con eritrocitos sirvieron como controles. Terminadas las diluciones, se agregaron $50 \mu \mathrm{lde}$ la suspensión de eritrocitos al 3\% (v/v) y las lecturas se realizaron después de 2 horas de incubación de la placa a temperatura ambiente. La inhibición de la actividad hemaglutinante por diversos carbohidratos fue realizada con D-glucosa, D-maltosa, D-manosa, D-glucosamina, N-acetil glucosamina, D-galactosa, sacarosa, D-sorbitol y trealosa. Todos estos reactivos fueron adquiridos de Sigma Co., U.S.A. En las placas de microtitulación (96 pozos, Sigma Co., U.S.A.) se adicionaron a los primeros pozos de las filas $25 \mu \mathrm{l}$ de carbohidrato a concentraciones que varían desde 50 a $0,05 \mathrm{mM}$ en CTBS. Estos fueron diluidos serialmente con $25 \mu \mathrm{l}$ de CTBS ya presentes en los pozos hasta alcanzar una concentración final de 3,86 $\mu \mathrm{g} / \mathrm{ml}$. Las placas se mantuvieron en reposo por 5 minutos, para enseguida adicionárseles $50 \mu \mathrm{l}$ de una suspensión al 3\% (v/v) de eritrocitos tripsinizados del grupo O. Después de 2 horas en reposo a temperatura ambiente, se determinó la menor concentración de carbohidrato capaz de inhibir la aglutinación inducida por $3,86 \mu \mathrm{g} / \mathrm{ml}$ de lectina sobre eritrocitos tripsinizados del grupo $\mathrm{O} \mathrm{Rh}^{+}$. Asimismo, se usaron los agentes quelantes EDTA (ácido etilendiamino tetraacético) y EGTA (ácido etilenglicol bis tetraacético; Sigma Co., USA) para ensayos de inhibición. En cada pocillo de prueba se agregaron $25 \mu \mathrm{l}$ de TBS más $25 \mu \mathrm{l}$ del respectivo agente quelante, y se hizo una dilución seriada en la misma fila hasta obtener concentraciones que variaron desde 50 hasta $0,10 \mathrm{mM}$. Se determinó la menor concentración de agente quelante capaz de inhibir la aglutinación inducida por $3,86 \mu \mathrm{g} / \mathrm{ml}$ de lectina sobre eritrocitos tripsinizados del grupo $\mathrm{O}$.

Análisis de la secuencia aminoacídica: El análisis de aminoácidos fue realizado en un analizador automático de aminoácidos PICO TAG (Sistema Waters), donde la identificación de los aminoácidos fue realizada a través de una cromatografía en HPLC del producto feniltiocarbamil del aminoácido proveniente de la derivatización con fenilisotiocianato de los aminoácidos que se obtengan por hidrólisis ácida. Esta forma de cromóforos pudo ser detectada en concentraciones de 1 pmol, según la metodología descrita por Henrikson y Meredith (1984). Para la determinación de la secuencia N-terminal (según Edman \& Begg, 1967), 40 nmoles de la muestra reducida con $1 \mathrm{M}$ de DTT obtenida en la cromatografía de fase reversa en HPLC fueron colocados en el secuenciador automático modelo 477 (Applied Biosystems). La secuencia N-terminal de la fracción fue comparada con la secuencia de otras lectinas usando el servidor electrónico http://www.ncbi.nlm.nih.gov/BLAST/ que también brinda acceso directo a bases de datos de proteínas como SWISS-PROT.

\section{RESULTADOS Y DISCUSIÓN}

\section{PURIFICACIÓN DE LA LECTINA DE TARA CSLEC}

El perfil cromatográfico resultante de la primera columna de exclusión molecular (Figura 1) muestra la presencia de 2 picos proteicos, siendo el pico 2 el único que mostró actividad hemaglutinante. El perfil cromatográfico de la segunda columna de exclusión molecular (Figura 2) también resultó en la presencia de 2 picos: 2-1 y 2-2, siendo el pico 2-2 el único con actividad hemaglutinante, pese a encontrarse en menor concentración.

Después de cargar esta fracción a una columna de HPLC de fase reversa, se obtuvieron tres picos denominados 2-2A, 2-2B y 2-2C (Figura 3 ). De éstos, el pico 2-2C fue el único que presentó actividad hemaglutinante, lo que sugiere que correspondería a la lectina altamente purificada. Esta señal de la lectina eluyó a los 37 minutos con una concentración de 58\% del tampón B, mientras que las señales menores eluyeron en tiempos anteriores y en menores concentraciones del tampón B. Este resultado sugiere que la lectina tendría un mayor 


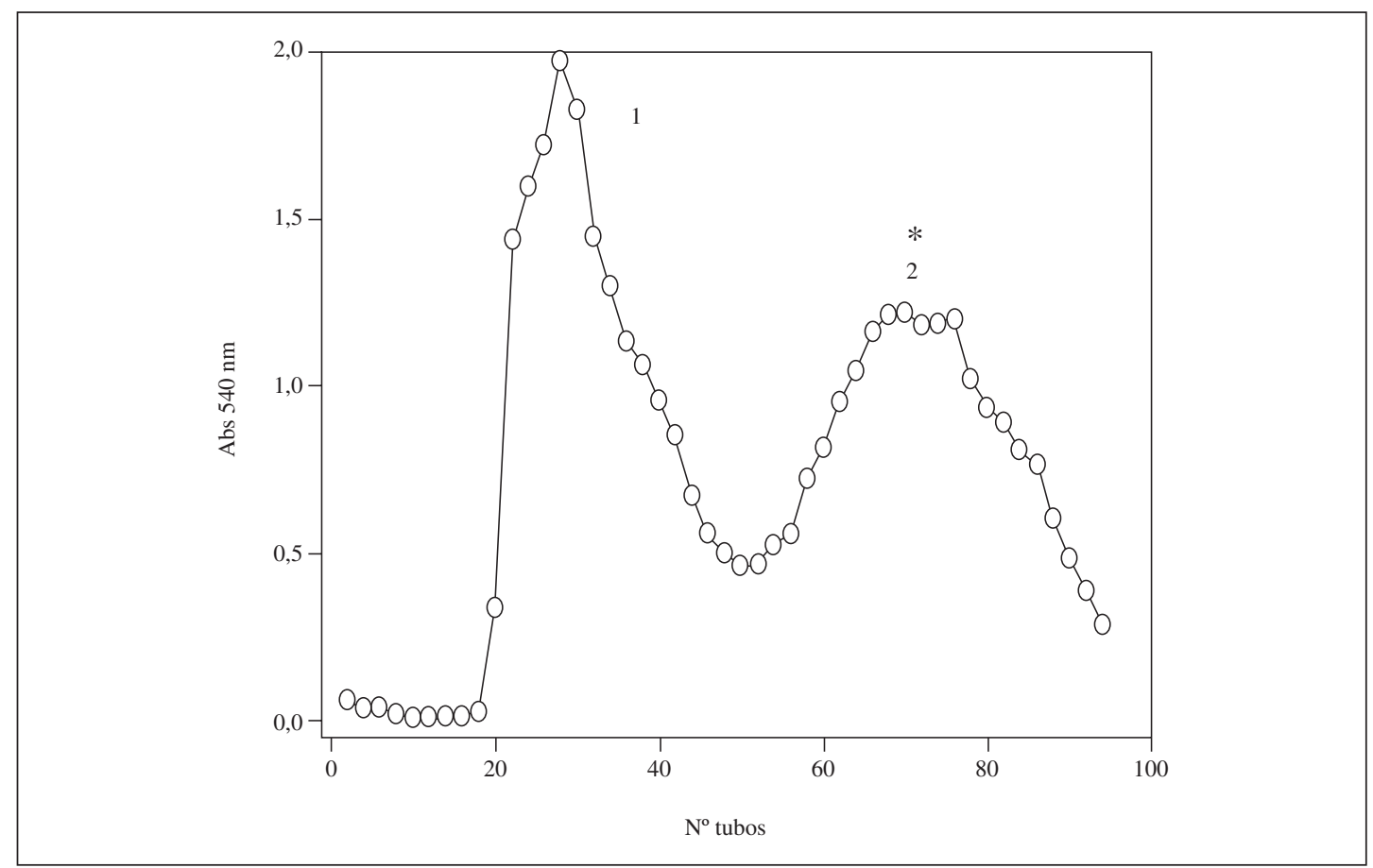

Figura 1. Cromatografía de exclusión molecular del extracto salino de semillas de C. spinosa en Sephadex G-100. Se colectaron fracciones de $3 \mathrm{ml} /$ tubo. La absorbancia de las fracciones fue monitoreada a $540 \mathrm{~nm}$. El pico 2 (*) fue el único de los picos que presentó actividad hemaglutinante.

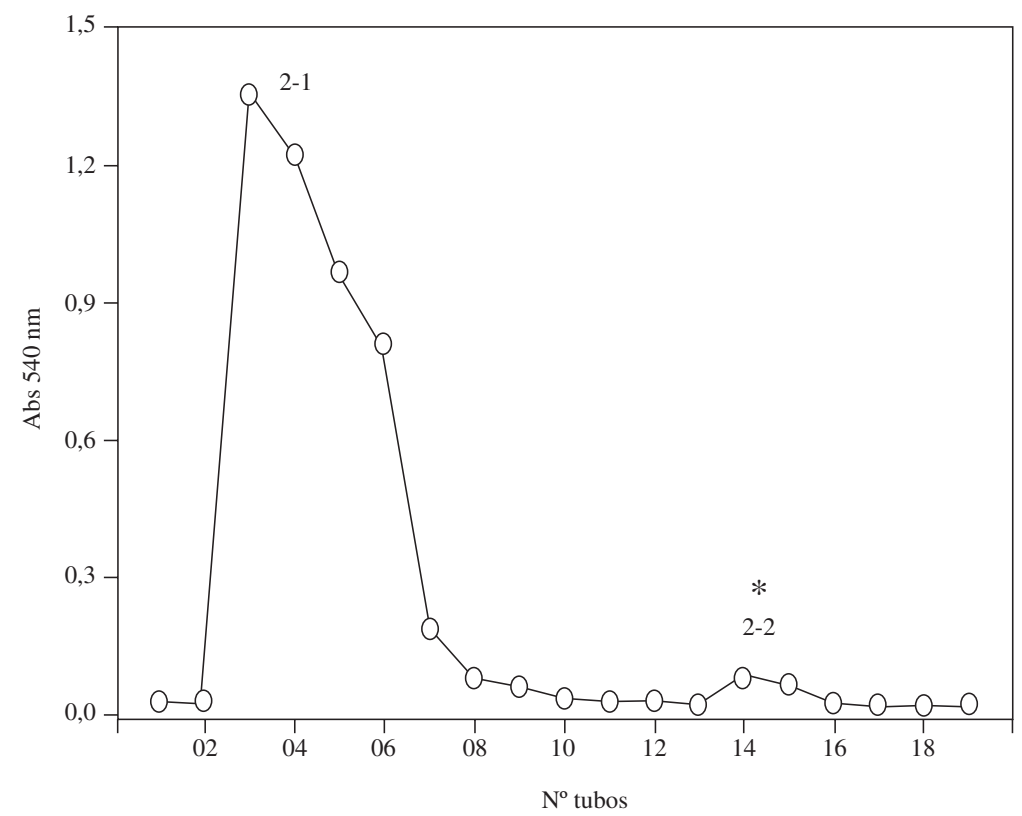

Figura 2. Cromatografía de exclusión molecular en Sephadex G-75 correspondiente al pico 2 de la etapa de purificación anterior, procedente del extracto de semillas de C. spinosa. Se colectaron fracciones de $3 \mathrm{ml} /$ tubo y la absorbancia fue monitoreada a $540 \mathrm{~nm}$. El pico 2-2 fue el único que presentó actividad hemaglutinante. 


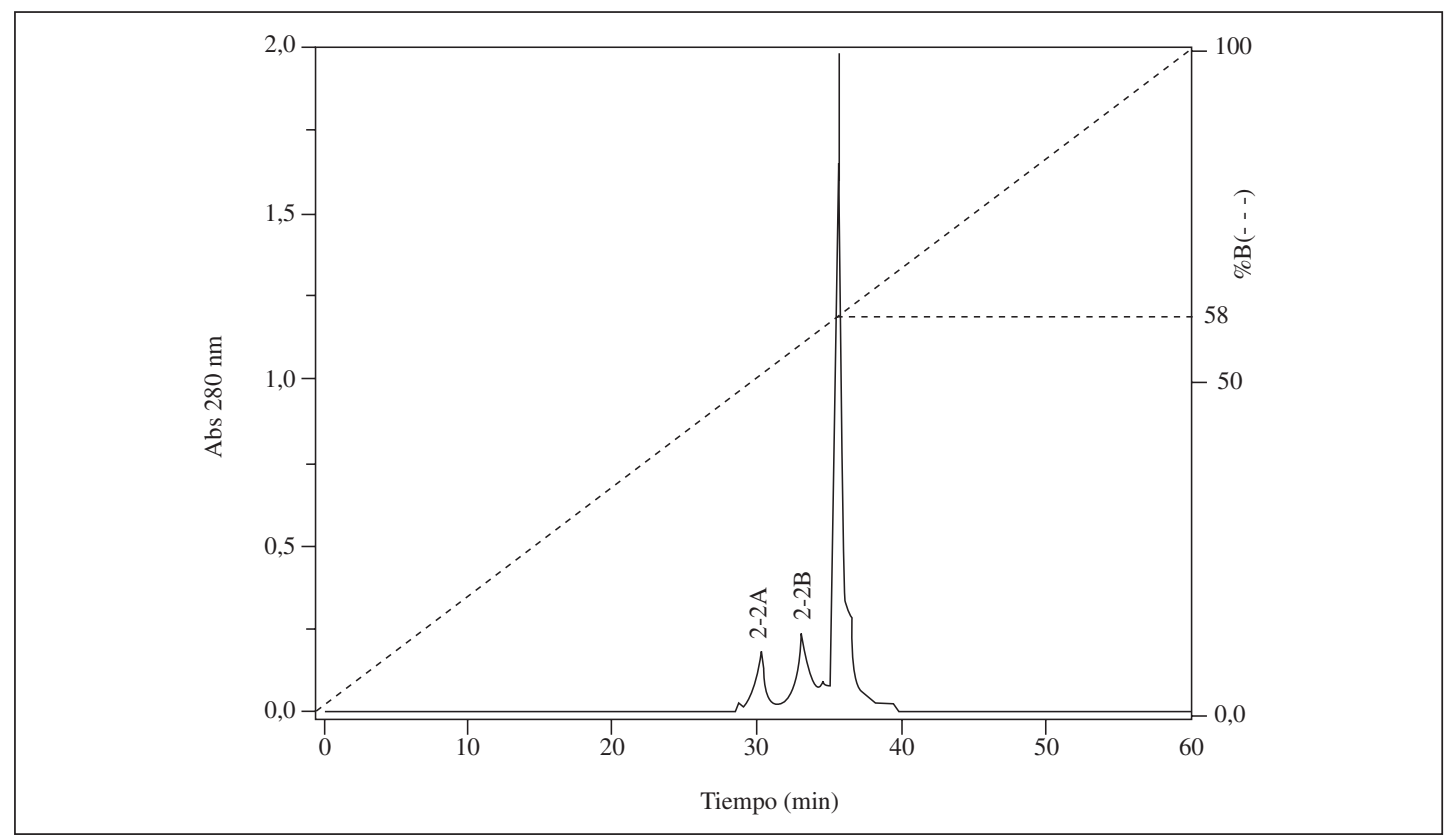

Figura 3. Purificación de CsLEC por HPLC de fase reversa. 5 mg de la fracción 2-2 de la segunda columna de exclusión molecular fueron inyectados a la columna. El monitoreo de la corrida se realizó a $280 \mathrm{~nm}$, siendo las fracciones colectadas a un flujo constante de $1 \mathrm{ml} / \mathrm{min}$. La fracción con actividad hemaglutinante corresponde a 2-2 C.

porcentaje de aminoácidos hidrofóbicos en relación a los dos anteriores, lo que al parecer indicaría que se trata de una proteína altamente compacta y estable.

Para corroborar la naturaleza proteica y la masa de la lectina purificada, la fracción 2-2 C proveniente de la purificación en HPLC de fase reversa fue cargada en un gel denaturante de poliacrilamida. El análisis por SDS-PAGE evidencia que se trata de una proteína de bajo peso molecular, de aproximadamente 29 KDa (Figura 4). Asimismo, se puede apreciar la homogeneidad y pureza de la lectina obtenida, al no encontrarse otras bandas en relación al extracto crudo (EC).

A su vez, como se puede apreciar en la Figura 5, se determinó la masa molecular de la fracción con actividad hemaglutinante correspondiente a CsLEC, a través de una regresión semilogarítmica haciendo uso del programa para PC Origin 6.0, indicando que la lectina obtenida posee una masa molecular de $29,19 \mathrm{KDa}$.

\section{ACTIVIDAD HEMAGLUTINANTE DE LA CSLEC}

Como se puede apreciar en la Tabla 1, se practicaron diluciones seriadas de la fracción 2-2 C

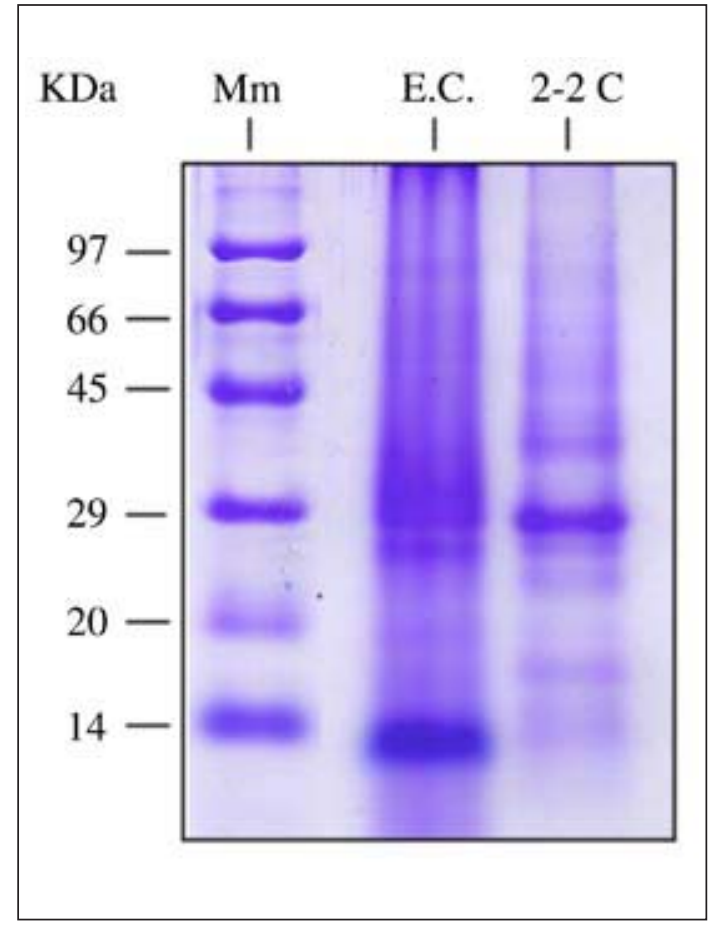

Figura 4. Electroforesis en gel de poliacrilamida (12,5\%) en presencia de dodecil sulfato de sodio (SDS). E.C. $=$ extracto crudo de semillas de C. spinosa, $2-2 \mathrm{C}$ = fracción con actividad hemaglutinante procedente de la purificación en HPLC de fase reversa. $\mathrm{Mm}$, marcadores de masa molecular. 


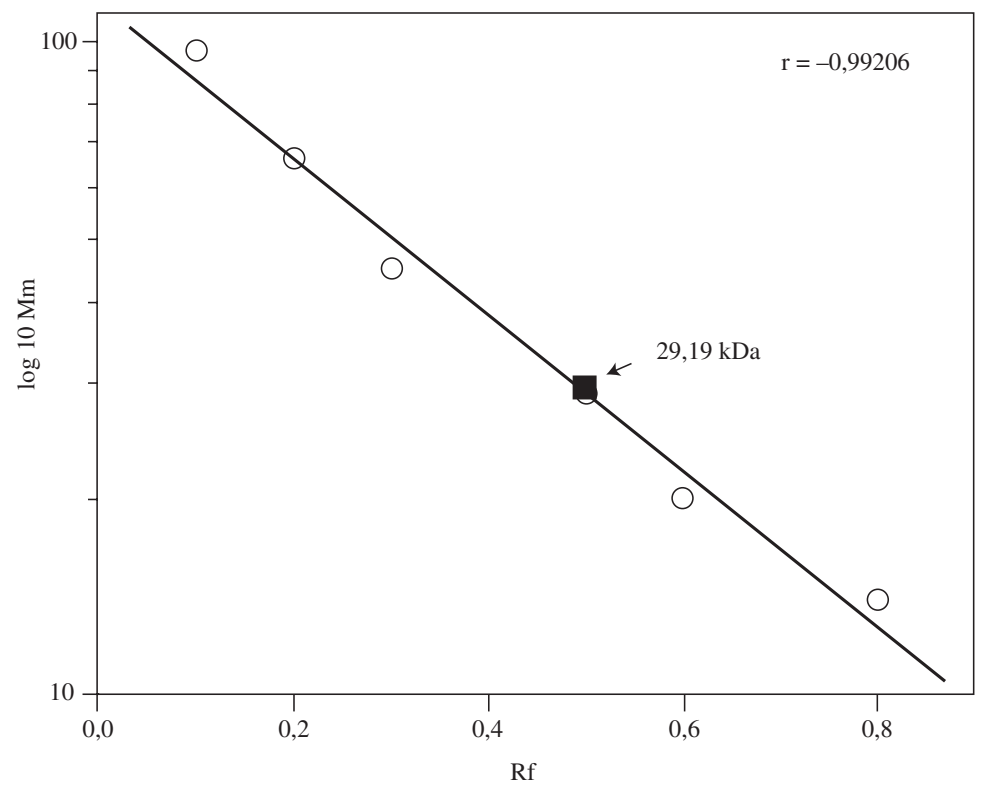

Figura 5. Determinación de la masa molecular relativa de la fracción hemaglutinante 2-2 C (CsLEC), procedente de semillas de Caesalpinia spinosa (33,38 kDa). $\log 10 \mathrm{Mm}=$ logaritmo de base 10 de los marcadores de masa molecular en kilodaltons; $\mathrm{Rf}=$ distancia migrada de los marcadores entre la distancia total del gel; $\mathrm{r}=$ coeficiente de regresión y correlación inversa.

(CsLEC), las que fluctuaron desde 247 hasta 0,24 $\mu \mathrm{g} / \mathrm{ml}$ para determinar la concentración mínima hemaglutinante (CMH) (Figura 6), la cual fue detectada hasta el pozo donde se observaba una película uniforme de eritrocitos. Se pudo determinar que la $\mathrm{CMH}$ para los eritrocitos del grupo $\mathrm{O}^{+}$fue de $7,73 \mu \mathrm{g} / \mathrm{ml}$, para el grupo A de $7,73 \mu \mathrm{g} / \mathrm{ml}$, para el grupo $\mathrm{B}$ de $3,86 \mu \mathrm{g} / \mathrm{ml}$, y para el grupo $\mathrm{AB}$ de $15,46 \mu \mathrm{g} / \mathrm{ml}$ de CsLEC.

De acuerdo con la Tabla 1, la actividad hemaglutinante de la CsLEC (con una concentración mínima de $3,86 \mu \mathrm{g} / \mathrm{ml}$ ) frente a los eritrocitos humanos del grupo $\mathrm{B} \mathrm{Rh}^{+}$fue inhibida por los azúcares: D-glucosa, D-maltosa, D-manosa, D-glucosamina y $\mathrm{N}$-acetil glucosamina, todos a una concentración de 3,25 mM y requirió una mayor concentración de otros azúcares tales como: D-galactosa, sacarosa, D-sorbitol y trealosa $(12,5 \mathrm{mM})$, tal como se indica en la Tabla 2.

En la Tabla 3 se observa que la hemaglutinación inducida por CsLEC $(3,86 \mu \mathrm{g} / \mathrm{ml})$ sobre eritrocitos del grupo sanguíneo $\mathrm{B} \mathrm{Rh}^{+}$es específicamente inhibida por EDTA $(0,31 \mathrm{mM})$ y en una proporción ligeramente menor que el EGTA $(0,63 \mathrm{mM})$, lo cual indica que la CsLEC es una lectina tipo C, ya que en presencia de estos agentes quelantes pierde su actividad aglutinante. Esto concuerda con la necesidad que tienen, por ejemplo, las lectinas de leguminosas de requerir iones para poder ligarse a carbohidratos. Iones divalentes como el calcio y manganeso se encargarían de mantener la estructura tridimensional de estas proteínas con sus sitios reactivos altamente conservados, los cuales están localizados en una de las dos asas del sitio de ligamiento de carbohidratos.

Tabla 1

Hemaglutinación inducida por CsLEC en eritrocitos humanos

\begin{tabular}{|c|c|}
\hline $\begin{array}{c}\text { Grupo sanguíneo } \\
\text { humano }\end{array}$ & $\begin{array}{c}\text { Concentración mínima } \\
\text { hemaglutinante }(\mu \mathrm{g} / \mathrm{ml})\end{array}$ \\
\hline $\mathrm{AB}$ & 15,46 \\
$\mathrm{~A}$ & 7,73 \\
$\mathrm{~B}$ & 3,86 \\
$\mathrm{O}$ & 7,73 \\
\hline
\end{tabular}


Tabla 2

Inhibición de la actividad hemaglutinante de la fracción 2-2 C (CsLEC) por carbohidratos

\begin{tabular}{|l|c|}
\hline Carbohidrato & $\begin{array}{c}\text { Concentración mínima } \\
\text { inhibitoria }(\mathbf{m M})\end{array}$ \\
\hline D-Glucosa & 3,25 \\
D-Maltosa & 3,25 \\
D-Manosa & 3,25 \\
D-Glucosamina & 3,25 \\
N-acetilglucosamina & 3,25 \\
D-Galactosa & 12,5 \\
Sacarosa & 12,5 \\
D-sorbitol & 12,5 \\
Trealosa & 12,5 \\
\hline
\end{tabular}

Tabla 3

Inhibición de la actividad hemaglutinante de la CsLEC por agentes quelantes y DTT

\begin{tabular}{|l|c|}
\hline Agente Inhibidor & $\begin{array}{c}\text { Concentración mínima } \\
\text { inhibitoria }(\mathbf{m M})\end{array}$ \\
\hline EDTA & 0,31 \\
EGTA & 0,63 \\
DTT & n.i. \\
\hline
\end{tabular}

\section{ANÁLISIS DE LA COMPOSICIÓN AMINOACÍDICA DE CSLEC}

La lectina CsLEC fue sometida a hidrólisis ácida $(\mathrm{HCl} 6 \mathrm{~N})$ y a derivatización por PITC para obtener la composición global de aminoácidos (Tabla 4), donde los de naturaleza ácida constituyen

Tabla 4

Composición de aminoácidos de la CsLEC. Donde $\mathrm{m}$ aa, es mol de aminoácido; masa molecular de aminoácido por proteína; \% porcentaje

\begin{tabular}{|l|c|c|c|c|c|}
\hline Naturaleza & Tipo & Sigla & $\begin{array}{c}\text { Razón Molar } \\
\text { Aa./Prot. }\end{array}$ & \% & $\begin{array}{c}\text { Masa aa/Mol } \\
\text { proteína }\end{array}$ \\
\hline Ácido & Asp & D & 23 & 9,4 & $2.647,00$ \\
\hline Ácido & Glu & E & 17 & 6,9 & $2.195,21$ \\
\hline Polar s/c & Ser & S & 16 & 6,5 & $1.393,44$ \\
\hline Hidrofóbico & Gly & G & 15 & 6,1 & 856,05 \\
\hline Básico & His & H & 3 & 1,2 & 411,48 \\
\hline Básico & Arg & R & 12 & 4,9 & $1.874,52$ \\
\hline Polar s/c & Thr & T & 18 & 7,3 & $2.000,16$ \\
\hline Hidrofóbico & Ala & A & 10 & 4,0 & 710,90 \\
\hline Hidrofóbico & Pro & P & 21 & 8,6 & $2.039,73$ \\
\hline Polar s/c & Tyr & Y & 2 & 0,8 & 228,30 \\
\hline Hidrofóbico & Val & V & 11 & 4,5 & $1.794,65$ \\
\hline Hidrofóbico & Met & M & 2 & 0,8 & 262,48 \\
\hline Polar s/c & Cys & C & 6 & 2,4 & 618,84 \\
\hline Hidrofóbico & Ile & I & 12 & 4,9 & $1.238,01$ \\
\hline Hidrofóbico & Leu & L & 15 & 6,1 & $1.697,55$ \\
\hline Hidrofóbico & Phe & F & 54 & 22,1 & $7.948,26$ \\
\hline Básico & Lys & K & 7 & 2,8 & 897,33 \\
\hline & Trp & & n.d. & n.d. & n.d. 6,1 \\
\hline & Total & & $\mathbf{2 4 4 0 0 , 0}$ & $\mathbf{2 8 . 8 1 3 , 1 2 9 1}$ \\
\hline
\end{tabular}


el $16,3 \%$, los básicos $8,9 \%$, los neutros $17,0 \%$ y los hidrofóbicos 57,8\%. Así, los grupos ácido y básico estarían condicionando la carga de la lectina. En la misma tabla se observa que el aminoácido presente en mayor cantidad es la fenilalanina (Phe; $22,1 \%$ ), mientras que los menos abundantes son tirosina y metionina, cada uno con $0,8 \%$. En base a lo señalado anteriormente, podemos decir que la CsLEC es una proteína hidrofóbica. La presencia de seis residuos de cisteínas nos sugiere la posible formación de tres puentes disulfuro, lo que estaría relacionado con la estabilidad de la proteína.

La Figura 6 muestra la secuencia de un segmento de la región $\mathrm{N}$-terminal de la CsLEC compuesta de 31 aminoácidos (D N Q R S F S F N R F N A A P N E N D L L F Q G D A S V S S T), la cual fue obtenida empleando un secuenciador automático de aminoácidos que emplea la técnica de degradación de Edman. Asimismo, se observa que el grado de homología secuencial de la región $\mathrm{N}$-terminal va de 67,9 a 53,6\% de identidad, en relación a las seis proteínas con mayor homología aminoacídica a la CsLEC (empleando el banco de datos de proteínas Swiss-Prot). El análisis de homología secuencial demostró que la CsLEC tiene similitud $(67,9 \%)$ con la leucoaglutinina (lectina) de Maackia amurensis (Fabaceae, Papilionoideae) con sialillactosa.

Son alrededor de 500 las lectinas aisladas y caracterizadas. Todas estas lectinas forman un grupo heterogéneo de proteínas debido a sus claras diferencias en estructura, especificidad y actividades biológicas. Recientemente las lectinas vegetales han sido clasificadas en base a análisis estructurales y datos sobre homología de secuencias en 7 familias de proteínas relacionadas estructural y evolutivamente: (1) lectinas de leguminosas, (2) lectinas ligadoras de quitina con dominios de heveína, (3) lectinas ligadoras de manosa de monocotiledóneas, (4) proteínas inactivadoras de ribosomas tipo II, (5) las amarantinas, (6) lectinas relacionadas con jacalina y (7) lectinas del floema de Cucurbitáceas (Peumans y Van Damme, 2001).

En el presente estudio se ha encontrado que la lectina de Caesalpinia spinosa (CsLEC) purificada a partir de semillas corresponde a una proteína con un alto porcentaje de aminoácidos hidrofóbicos, lo que al parecer indicaría que se trata de una proteína altamente compacta y estable, y con un peso molecular de alrededor de $29 \mathrm{KDa}$. Oliveira et al. (2003) encontraron que la lectina purificada a partir del fruto (vaina) de la tara presentó un alto número de residuos ácidos e hidrofóbicos, y su peso molecular fue de $\sim 12,5 \mathrm{kDa}$. En ambas lectinas purificadas de tara (semilla y fruto) existe un alto contenido de aminoácidos hidrofóbicos, pero el peso molecular fue mayor en la semilla $(\sim 29,19 \mathrm{kDa})$ que en la vaina. Esta diferencia indicaría que las lectinas distribuidas en las semillas y frutos podrían pertenecer a diferentes familias y tipos de lectinas. Entre algunas de las lectinas con peso molecular parecido a la CsLEC se encuentran: la lectina purificada de semillas de Phaseolus vulgaris (isoforma PHA-L) con un peso molecular de $32 \mathrm{kDa}$ y con la capacidad de aglutinar leucocitos; la lectina purificada de semillas de Phaseolus vulgaris (isoforma PHA-E) con un peso molecular de $34 \mathrm{kDa}$ y con la capacidad de aglutinar eritrocitos (Chrispeels y Raikhel, 1991). No obstante, existen lectinas de peso molecular más elevado como son: la lectina de $40 \mathrm{kDa}$ purificada de semillas de Talisia esculenta (Freire et al., 2001); la lectina de $78 \mathrm{kDa}$ purificada de

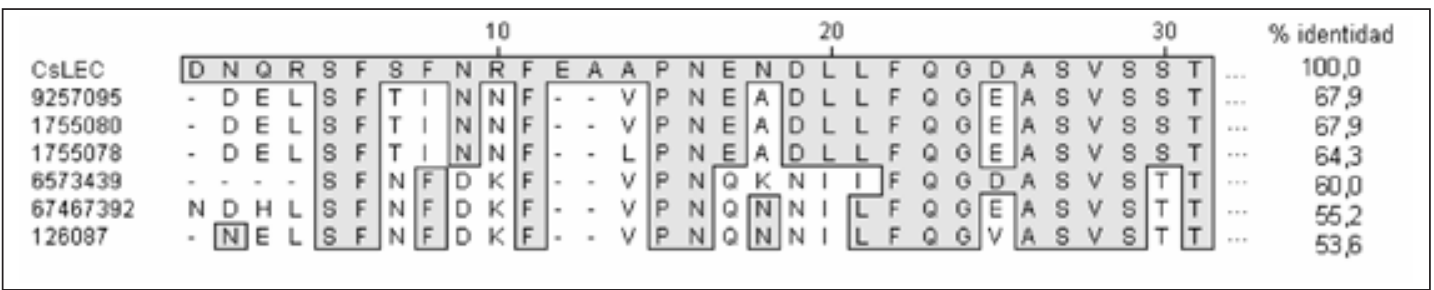

Figura 6. Alineamiento de la secuencia N-terminal de CsLEC con otras secuencias reportadas en la base de datos SWISS-PROT. El alineamiento de los residuos aminoacídicos fue realizado con la ayuda del programa DNA Star (CA. USA). Las regiones sombreadas representan regiones consenso de la proteína. Entre las seis proteínas comparadas están: 9257095, leucoaglutinina (lectina) de Maackia amurensis con Sialillactosa (Kawaguchi et al., 1974); 1755080, precursor de la lectina de Maackia amurensis (Van Damme et al., 1997); 1755078, precursor de la lectina extraída de la corteza de Maackia amurensis (Van Damme et al., 1997); 6573439, lectina Ii de Ulex europaeus (Hamelryck et al., 1998); 67467392, lectina I (CSA-I) Anti-H(O) de Cytisophyllum sessilifolium (Konami et al., 1992); 126087, lectina I (lectina de semilla Anti-H(O)) (LAA-I) de Laburnum alpinum (Konami et al., 1991). 
semillas de Lepechinia bullata capaz de aglutinar eritrocitos que exponen el antígeno Tn (GalNAc $\alpha$ O-Ser/Thr), un marcador específico de muchos carcinomas humanos (Sanabria et al., 2001); la lectina ligadora de manosa de $58 \mathrm{kDa}$ purificada de semillas de Parkia discolor (Leite et al., 2001) y la lectina de naturaleza ácida (123,5 kDa) extraída de semillas de Luetzelburgia auriculata que posee la capacidad de aglutinar eritrocitos de conejo siendo inhibida por ácido N-acetilD-neuramínico (Oliveira et al., 2001).

La CsLEC es capaz de aglutinar preferentemente eritrocitos del grupo B Rh+ $(3,86 \mu \mathrm{g} / \mathrm{ml})$ y de ser inhibida por D-glucosa, D-maltosa, D-manosa, D-glucosamina, N-acetilglucosamina $(3,25 \mathrm{mM}) \mathrm{y}$ el agente quelante EDTA $(0,31 \mathrm{mM})$, esto indicaba que sería una lectina tipo $\mathrm{C}$ dependiente de iones divalentes, tales como el calcio y manganeso.

\section{LITERATURA CITADA}

AYOUBA, A.; CAUSSE, H.; VAN DAMME, E.; PEUMANS, W.; CAMBILLAU, C.; ROGÉ, P. 1994. Interactions of plant lectins with the components of the bacterial cell wall peptidoglycan. Biochem Syst. Ecol. 22: 153-159.

CARLINI, C.R.; GROSSI-DE-SÁ, M.F. 2002. Plant toxic proteins with insecticidal properties. A review on their potentialities as bioinsecticides. Toxicon 40 (11):1515-39.

CASTILLO-VILLANUEVA, A.; ABDULLAEV, F. 2005. Lectinas vegetales y sus efectos en el cáncer. Revista de Investigación Clínica. Vol. 57. N¹. 55-64.

CARVALHO, M.; SGARBIERI, V. 1998. Relative importance of phytohemagglutinin (lectin) and trypsin-chymotrypsin inhibitor on bean (Phaseolus vulgaris $L$ ) protein absorption and utilization by the rat. J. Nutr. Sci. Vitaminol. 44(5): 685-696.

CHRISPEELS, M.; RAIKHEL, N. 1991. Lectins, Lectins genes, and their role in plant defense. Plant Cell. Vol. 3, 1-9.

COSTA, F.; SAMPAIO, A.; NEVES, S.; ROCHA, M.; BENAVIDES M.; FREITAS, A. 1999. Purification and characterization of a lectin from the red marine alga Amansa multifida. Physiol. Mol. Biol. Plants. 5: 53-61.

EDMAN, P.; BEGG, G. 1967. A protein sequencer. Eur $J$ Biochem. 1: 80-91.

FREIRE, M.; MACHADO, O.; SMOLKA, M.; MARANGONI, S.; NOVELLO, J.; MACEDO, M. 2001a. Isolation and characterization of isolectins from Talasia esculenta seeds. J. Protein. Chem.20 (6): 495-500.

FREIRE, M.; SILVA, A.; LIMA, M.; MARANGONI, S.; NOVELLO, J.; MACEDO, M. 2001b. TEL a novel lectin from Talasia esculenta seeds: isolation and cell migration inducing. 19th INTERLEC. Brazil.

HAMELRYCK, T; BOUCKAERT, J.; WYNS, L. 1998. Legume Lectin Structure. Biochim. Biophys. (1): 9-36.
Concerniente al estudio de homología secuencial se determinó que ésta pertenece a la familia de lectinas vegetales de Leguminosas, mostrando $67,9 \%$ de similitud con la leucoaglutinina de Maackia amurensis (Fabaceae, Papilionoideae) con sialillactosa y el precursor de la lectina de Maackia amurensis.

En un futuro, conociendo la estructura y función de la lectina de tara, podrían realizarse estudios frente a bacterias, hongos, virus y células tumorales, que causan daños a las plantas y el hombre.

\section{AGRADECIMIENTO}

Agradecemos al Dr. José Casaretto (Universidad de Talca, Chile) por sus sugerencias y revisión técnica de la presente investigación.

HENRIKSON, R.; MEREDITH, S. 1984. Amino acid analysis by reverse-phase high performance liquid chromatography in differentiating mouse astrocytes in primary culture. Dev. Neurosci. 1: 226-267.

HUDAK, K.; WANG P.; TUMER, N. 2000. A novel mechanism for inhibition of translation by pokeweed antiviral protein: depurination of the capped RNA template. $R N A$. 6: 369-380.

KAWAGUCHI, T.; MATSUMOTO, I.; OSAWA, T. 1974. Studies on hemagglutinins from Maackia amurensis seed. J. Biol. Chem. 249 (9), 2786-2792

KONAMI, Y.; YAMAMOTO, K.; TOYOSHIMA, S.; OSAWA, T. 1991. The primary structure of the Laburnum alpinum seed lectin. FEBS Lett. 286 (1-2), 33-38.

KONAMI, Y.; YAMAMOTO, K.; OSAWA, T.; IRIMURA, T. 1992. Correlation between carbohydrate-binding specificity and amino acid sequence of carbohydrate-binding regions of Cytisus-type anti-H(O) lectins. FEBS Lett. 304 (2-3), 129-135.

LAEMMLI, U. 1970. Clevage of structural proteins during the assembly of the head of bacteriophage T4. Nature. 227 (259): 680-685.

LEITE, K.; RAMOS, M.; CASTELLÓN, R.; MAIA, C.; GURGEL, M.; SOUZA, L.; CAVADA, B. 2001. Purification, chemical and immunochemical properties of a new lectin from Mimosoideae (Parkia discolor). 19th INTERLEC. Brazil.

OLIVEIRA, J.; MELO, V.; CAMARA, M.; VASCONCELOS, I.; BELTRAMINI, L.; MACHADO, O.; PEREIRA, S.; FERNÁNDEZ, C.; NUNES, E.; MONTEIRO, A. 2001. Purification and physicochemical characterization of a legume lectin from Luetzelburgia auriculata. 19th INTERLEC. Brazil. 
OLIVEIRA, M.; BELTRAMINI, L.; DE SIMONE, S.; NASSER, M.; SILVA-LUCCA, R.; KIAN, M.; VIEIRA, C.; ALMEIDA, M. 2003. Purification and partial characterization of a lectin from Caesalpinia tinctoria Domb, ex Dc fruits. J. Plant. Physiol. 15(2): 119-122. Brazil.

PEUMANS, W.; VAN DAMME E. 1995. Lectin as plant defense proteins. Plant Physiol. 109: 347-352

PEUMANS, W.; HAO, Q.; VAN DAMME, E. 2001. Ribosome-inactivating proteins from plants: more than RNA N-glycosidases? The FASEB Journal. 15: 1493-1506.

PEUMANS, W.; VAN DAMME, E.J.M. 2001. Taxonomical distribution of plant lectins. 19th INTERLEC. Brazil.

SANABRIA, E.; VEGA, N.; PÉREZ, G. 2001. Isolation and characterization of a lectin from Lepechinia bullata seed. $19^{\text {th }}$ INTERLEC. Brazil.

SHARON, N. Y H., LIS. 1989. Lectins as cell recognition molecules. Science. 246 (4927): 227-234.

TOYAMA, M.; CARNEIRO, E.; MARANGONI, S.; AMARAL, M.; VELLOSO, L.; BOSCHERO, A. 2001.

Isolation and characterization of a convulxin-like protein from Crotalus durissus collilineatus venom. J. Prot. Chem. 20(7): 585-591.

VAN DAMME, E.; BARRE, A.; ROUGE, P.; PEUMANS, W. 1997a. Molecular cloning of the bark and seeds lectins from Japanese pagoda tree (Sophora japonica). Plant Mol. Biol. 33(3): 523-536.

VAN DAMME, E.; VAN LEUVEN, F.; PEUMANS, W. 1997b. Isolation, characterization and molecular cloning of the bark lectins from Maackia amurensis. Glycoconj. J. 14(4): 449-456.

VILLARRUBIA, O.; DUBET, M.; MENÉNDEZ, J.; DE LA FUENTE, J.; NOA, E. 1995. Estudios de 2 preparados de fitohemaglutinina obtenidos por diferentes métodos. Rev. Cienc. Biol. (En prensa).

ZHU, K.; SHADE, R.; KOIWA, H.; SALZMAN, R.; NARASIMHAN, M.; BRESSAN, R.; HASEGAWA, P.; MURDOCK, L. 1998. Carbohydrate binding and resistance to proteolysis control insecticidal activity of Griffonia simplicifonia lectin II. Plant Biology. 95: 15123-15128. 